\title{
BONE AND ANTLER IMPLEMENTS \\ OF THE EARLY NEOLITHIC DNEPR-DVINA INTERFLUVE SETTLEMENTS: TECHNOLOGICAL AND FUNCTIONAL FEATURES, CONTEXT
}

(C) 2018

Malyutina Anna Andreevna, junior researcher of Experimental-Traceology Laboratory Institute of History of Material Culture of the Russian Academy of Sciences (Saint Petersburg, Russian Federation)

Abstract. In this paper we consider the results of the use-wear analysis of the bone and antler implements received as a result of excavation of the Early Neolithic settlements on the territory of Dnepr-Dvina interfluve. This kind of research is conducted for this category of archaeological material for the first time. For the analysis we have selected 27 bone, antler and teeth items occurring from two settlements of the Serteysky microregion - Serteya X and Rudnya Serteyskaya. The good preservation of items has allowed us to study macro- and microtraces connected with technology of processing of raw materials and receiving products, ways of usage of finished utilitarian and not utilitarian character items. The following categories of implements have been marked out: knives, awls, pendants, spear-heads, arrowheads, barbed points, preforms, fragments of items with processing traces. The obtained information is correlated to other materials of settlements - ceramics, stone artifacts, economic and cultural characteristic of settlements in general. Ceramic traditions in upper courses of the Western Dvina belong to 7 millennium BC. The earliest ceramic traditions are combined in Serteyskaya archaeological culture. Later, in materials of the Early Neolithic sites influence of Early Neolithic cultures of East Baltics is traced. As a result, on the territory of Podvinya the Rudnyanskaya Early Neolithic culture is formed.

Keywords: Early Neolithic; Serteyskaya culture; Rudnyanskaya culture; Dnepr-Dvina interfluve; Narva culture; use-wear analysis; choice of raw material; technology of processing; preliminary treatment; preform; secondary treatment; macrotraces; microtraces; function; typology; category; reconstruction; ancient hunting and fishing.

\section{ПЕТРОГРАФИЧЕСКИЙ АНАЛИЗ КЕРАМИКИ НОВОСВОБОДНЕНСКОЙ КУЛЬТУРЫ ИЗ ПОГРЕБЕНИЙ В КУРГАННОМ МОГИЛЬНИКЕ «КЛАДЫ»}

(C) 2018

Резепкин Алексей Дмитриевич, кандидат исторических наук, старший научный сотрудник отдела Центральной Азии и Кавказа

Институт истории материальной культуры РАН (г. Санкт-Петербург, Российская Федерация)

Аннотащия. Морфологический анализ керамики новосвободненской культуры до сих пор не проводился. В данной работе представлен анализ 19 фрагментов сосудов из погребений курганного могильника «Клады». В результате было выяснено, что состав глиняной массы, применяемой в изготовлении керамики, был весьма разнообразен: как цельные виды глин - известняковые, монтмориллонитовые, гидрослюдистые, так и в их разнообразных комбинациях - еще шесть вариантов. Причем почти половина сосудов (девять) была изготовлена из известняковых и монтмориллонитовых глин. Разнообразен и состав примесей - песок, шамот, известняк и дресва, также в различных смешанных вариантах. Меньше всего было фрагментов без примесей, всего четыре. Сосуды подвергались как окислительному обжигу, так и восстановительному. Комбинированному, окислительно-восстановительному обжигу были подвергнуты всего три экземпляра. Проведен сравнительный анализ майкопской и новосвободненской керамики. Таким образом, данный способ исследования керамики показал, что носители новосвободненской культуры обладали большим опытом керамического производства, что позволяло им использовать широкий ассортимент глин, причем в их разнообразных комбинациях, и способов обжига в изготовлении керамики.

Ключевые слова: Северный Кавказ; эпоха ранней бронзы; четвертое тысячелетие; Майкопская культура; новосвободненская культура; керамика; морфологический анализ; виды глин; примеси керамики; восстановительный обжиг; окислительный обжиг; петрографический анализ; технология изготовления керамики.

До сих пор керамика новосвободненской культуры рассматривалась с точки зрения типологии [110]. Следующий этап изучения керамического комплекса культуры, как представляется, должен включать в себя технологию изготовления и петрографический анализ, что позволит более обоснованно показать не только типологические, но и иные параметры отличия новосвободненской керамики от майкопской. В данной работе впервые представлен петрографический анализ новосвободненской керамики из погребений курганного могильника «Клады».

Обр. К-1. Плотная, тонкостенная (7 мм) керамика черного цвета, лощеная (рис. $1: K-1-1-3$ ).
Состав: глины известковые, жирные, кластического (обломочного) материала - 5-10\%, кварц, полевой шпат.

Отощитель: дробленый известняк (20\%), размер 0,5-1 мм, шамот (10\%) (высушенная ожелезненная глина), отдельные углистые частицы (0,7-1,5 мм), песок кварц полевошпатового состава $(40 \%)(0,15-$ 0,5 мм). Пористость: округлые поры (5\%), размером 2-3 мм. Температура обжига $800-850^{\circ} \mathrm{C}$ (остатки карбоната, невыгоревшей органики, угля), обжиг восстановительный, кратковременный.

Обр. К-2. Плотная, керамика серого цвета, лощеная с внешней поверхности (рис. $1: K-2-1-3$ ). 
Резепкин А.Д.

Петрографический анализ керамики новосвободненской культуры.

07.00.00 - исторические науки и археология

Состав: глины смешаннослойные, тощие, кластического (обломочного) материала - 20\%, кварц, полевой шпат.

Отощитель: дресва (20\%) метаморфических пород (средние плагиоклазы, флогопит) размер зерен 1-2 мм. Пористость: 5\%, поры округлые, образовавшиеся в результате выпадения зерен отощителя.

Температура обжига $800-900^{\circ} \mathrm{C}$, обжиг нейтральный, кратковременный, тонкодисперсная органика выгорела не полностью.

Обр. К-3. Плотная, толстостенная (15 мм) керамика ярко кирпичного цвета (рис. $1: K-2-1-3$ ).
Состав: глины монтмориллонитовые, тощие, кластического (обломочного) материала - 5-10\%, кварц, полевой шпат.

Отощитель: хорошо окатанный песок кварцполевошпатового состава (60\%), размер 0,5-1 мм, отдельные зерна шамота (высушенная ожелезненная глина).

Пористость: нет. Температура обжига 1000$1100^{\circ} \mathrm{C}$. Присутствуют игольчатые кристаллы волластонита (25\%), отмечается аморфизация глины. Возможно, первоначально глина была обогащена карбонатом. Обжиг окислительный, долговременный.

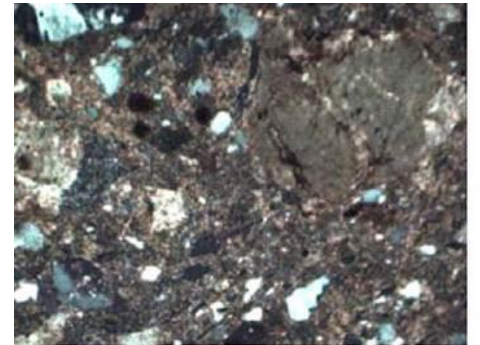

$\mathbf{K}-\mathbf{1}$
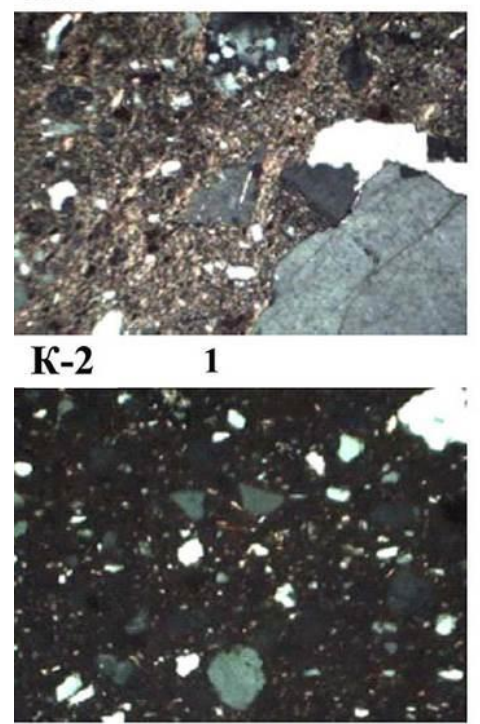

$\mathbf{K}-\mathbf{3}$

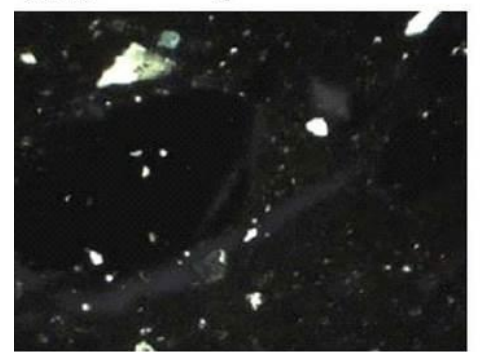

K-4

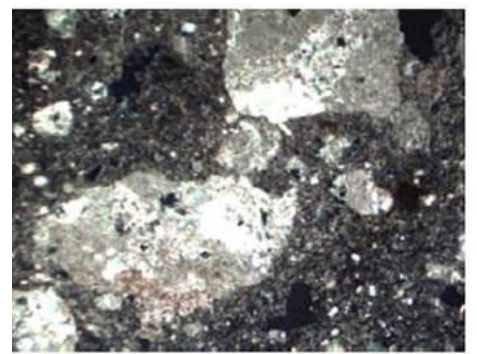

$\mathbf{K}-5$

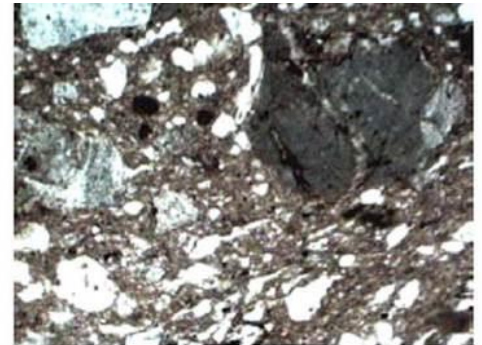

2

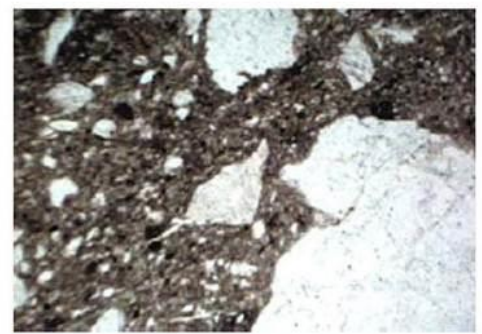

2

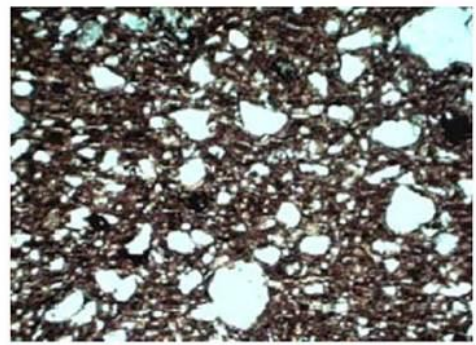

2

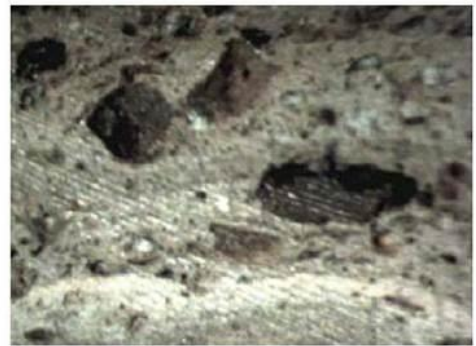

2

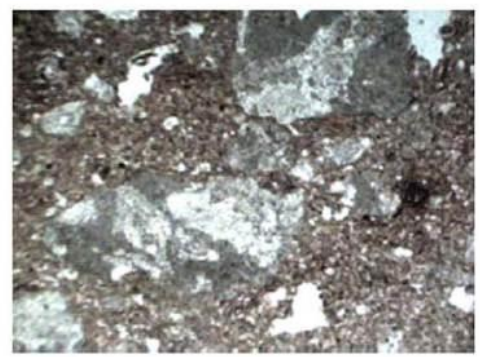

2

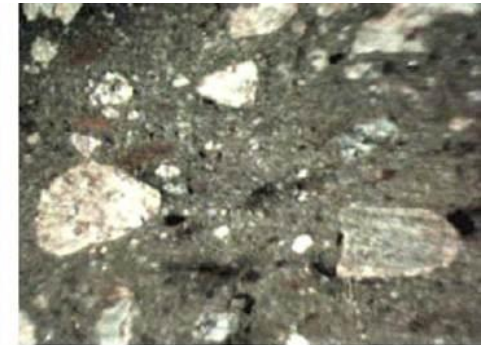

3

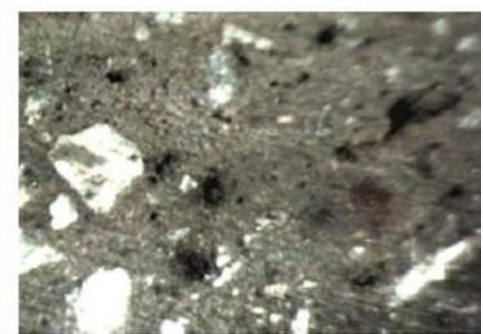

3

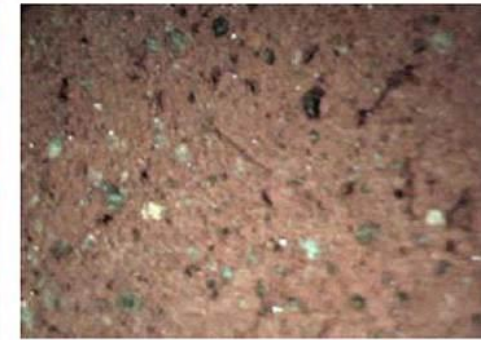

3

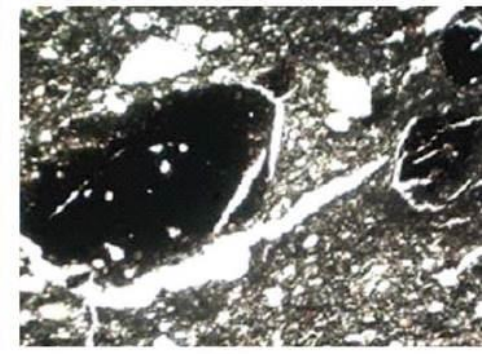

3

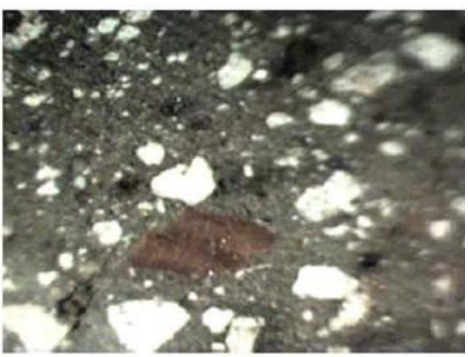

3

Рисунок 1 - Керамика из погребений курганного могильника «Клады».

Образцы керамики: $K-1 ; \kappa-2 ; \kappa-3 ; \kappa-4 ; \kappa-5$. Условные обозначения:

1 - ×65 (без анализаторов); 2- (в поляризационном свете); 3-×15 (под бинокуляром) 
Обр. К-4. Плотная, толстостенная (7 мм) керамика серого цвета во внутренней части, на внешних поверхностях - кирпичного цвета (рис. $1: K-4-1-3$ ).

Состав: глины каолинит-гидрослюдистого состава, тощие, кластического (обломочного) материала $25 \%$, кварц, полевой шпат.

Отощитель: песок $(25 \%)$ кварц-полевошпатового состава с включениями отдельных зерен песчаника, размер зерен $0,3-1$ мм, шамот $(5 \%)$ - обожженная керамика, размер 1-1,5 см. Добавлены зерна злаковых растений (15\%), зерна обожженные, размером до 2 мм. Пористость: $1 \%$, поры округлые, образовавшиеся в результате выпадения зерен отощителя. Температура обжига $800-1000^{\circ} \mathrm{C}$ (остатки карбоната, невыгоревшей органики, угля), обжиг окислительный, недостаточно длительный.
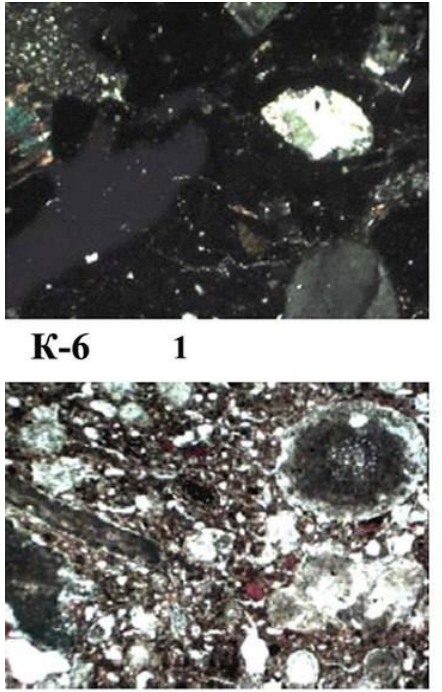

K-7

1

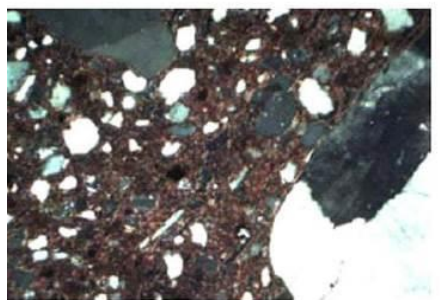

K-8

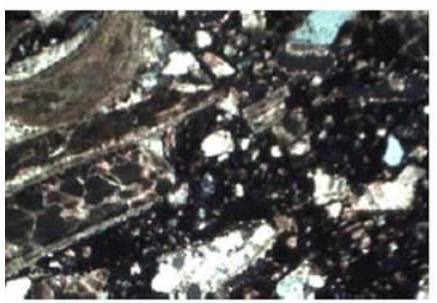

K-9

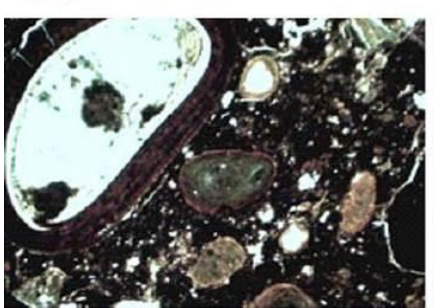

K-10

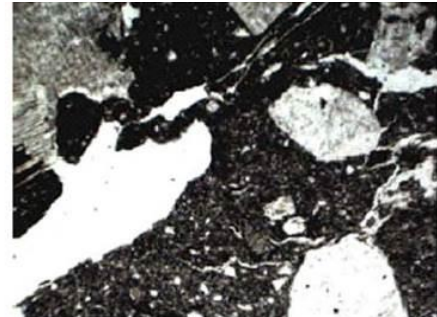

2

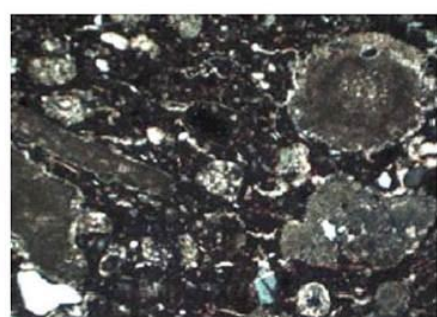

2

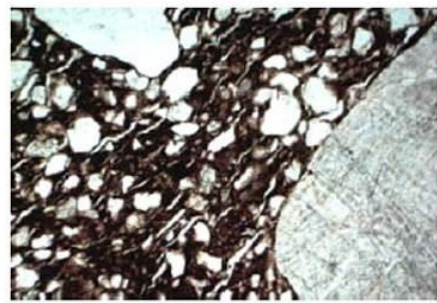

2

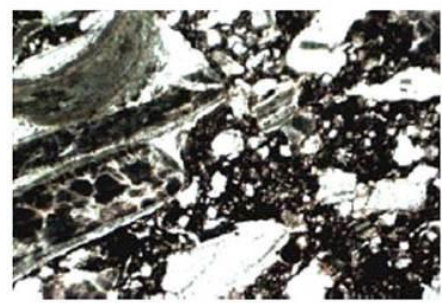

2

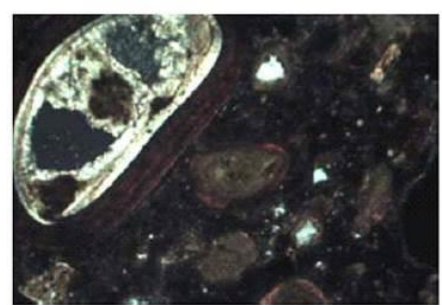

2
Обр. К-5. Плотная, тонкостенная (7 мм) керамика черного цвета, лощеная (рис. $1: K-5-1-3$ ).

Состав: глины известковые, жирные, кластического (обломочного) материала - 5-10\%, кварц, полевой шпат.

Отощитель: дробленый известняк (60\%), размер 0,5-1 мм, отдельные зерна шамота (высушенная ожелезненная глина), отдельные углистые частицы (0,7 мм). Пористость: нет. Температура обжига 800$850^{\circ} \mathrm{C}$ (остатки карбоната, невыгоревшей органики, угля), обжиг восстановительный, кратковременный.

Обр. К-6. Плотная, керамика серого цвета во внутренней части, на внешней поверхности - ярко кирпичного цвета (рис. $2: K-6-1-3$ ).

Состав: глины каолинит-гидрослюдистого состава, тощие, кластического (обломочного) материала $25 \%$, кварц, полевой шпат.

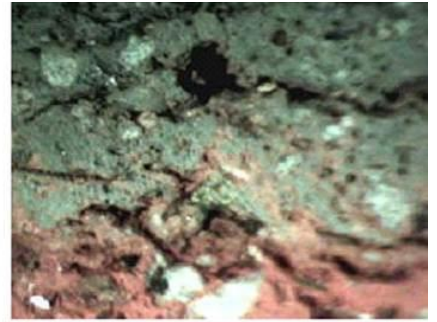

3

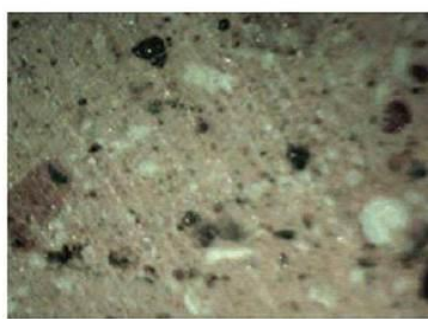

3

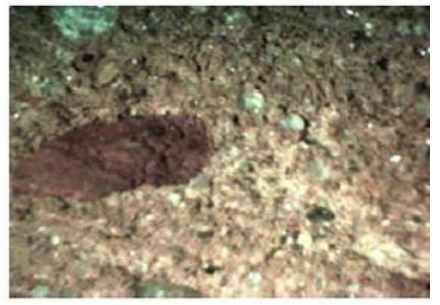

3

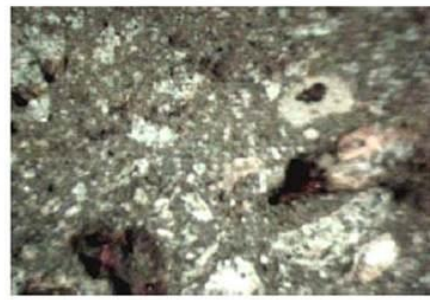

3

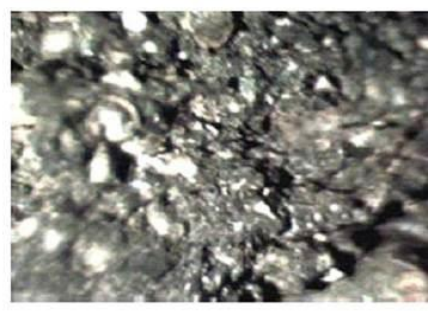

3

Рисунок 2 - Керамика из погребений курганного могильника «Клады».

Образцы керамики: $\kappa-6 ; \kappa-7 ; \kappa-8 ; \kappa-9 ; \kappa-10$. Условные обозначения:

1 - ×65 (без анализаторов); 2- (в поляризационном свете); 3-×15 (под бинокуляром) 
Отощитель: дресва (25\%) пород основного состава и метаморфических пород (средние полевые шпаты, амфибол, оливин, биотит) размер зерен 1-4 мм, зерна полевого шпата серпентизированы, растресканы, шамот (2\%) - обожженная керамика, размер 11,5 см. Пористость: 15\%, поры вытянутые, результат выгорания органических остатков. Температура обжига $800-1000^{\circ} \mathrm{C}$, обжиг окислительный, недостаточно длительный.

Обр. К-7. Плотная, толстостенная (14 мм) керамика розового цвета (рис. $2: K-7-1-3$ ).

Состав: глины известково-монтмориллонитовые, обогащенные гидроокислами и окислами железа, тощие, кластического (обломочного) материала $15 \%$, кварц, полевой шпат (ортоклаз). Известковые остатки (60\%) представлены различными мелкими морскими раковинами, мшанками, остатками растений, размером 0,3-0,7 мм, отдельные зерна гематита.

Соотношение $\mathrm{CaO}: \mathrm{Fe}_{2} \mathrm{O}_{3}$ превышает 2:1.

Отощитель: не использовался, встречаются отдельные зерна шамота того же состава, м.б. высушенная глина, размер 1-2 мм. Пористость: 5\%, поры округлые, образовавшиеся в результате выпадения раковин и зерен шамота, размером 0,35-1 мм. Температура обжига $800-850^{\circ} \mathrm{C}$ (остатки карбонатных раковин), обжиг окислительный, кратковременный.

Обр. К-8. Плотная, толстостенная (11 мм) керамика кирпичного цвета, на внешней поверхности черного цвета (рис. $2: K-8-1-3$ ).

Состав: глины монтмориллонитовые, тощие, кластического (обломочного) материала - 5-10\%, кварц, полевой шпат.

Отощитель: хорошо окатанный песок кварцполевошпатового состава с отдельными зернами песчаника, карбоната (60\%), размер 0,5-4 мм, отдельные зерна шамота (высушенная ожелезненная глина). Пористость: нет. Температура обжига 800$1000^{\circ} \mathrm{C}$, обжиг долговременный в окислительной среде, затем в восстановительной среде кратковременный обжиг.

Обр. К-9. Плотная, тонкостенная (7 мм) керамика розового цвета (рис. 2: $K-9-1-3$ ).

Состав: глины монтмориллонитовые, жирные, кластического (обломочного) материала - 5\%, кварц, полевой шпат.

Отощитель: песок полевошпатового состава (40\%), размер зерен 0,14-0,5 мм.

Измельченный ракушечник (40\%) - 1,3 мм.

Пористость: 5\%, поры округлые, образовавшиеся в результате выпадения раковин, размером до 1 мм. Температура обжига $800-850^{\circ} \mathrm{C}$ (остатки карбонатных раковин), обжиг окислительный, кратковременный.

Обр. К-10. Рыхлая, тонкостенная (7 мм) керамика черного цвета, лощеная.

Состав: глины известковые, жирные, кластического (обломочного) материала - 5-10\%, кварц, полевой шпат. Остатки и обломки раковин и железисто-карбонатных оолитов, железистых включений, размером 0,35-2 мм (рис. 2: $K-10-1-3$ ).

Отощитель: не использовался. Пористость: 5\%, поры вытянутые, образовавшиеся в результате выгорания органики, размером до 1 мм.

Температура обжига $800-850^{\circ} \mathrm{C}$ (остатки карбоната, невыгоревшей органики, угля), обжиг восстановительный, кратковременный.
Обр. К-11. Плотная, толстостенная (11 мм) керамика светло-серого цвета (рис. $3: \kappa-11-1-3$ ).

Состав: глины известковые, жирные, кластического (обломочного) материала - 1-2\%, полевой шпат.

Отощитель: дробленый доломит, обогащенный раковинами (70\%), размером 0,5-4 мм, отдельные зерна шамота, высушенной ожелезненной глины (0,5-0,7 мм), углистые включения (0,3-0,5 мм). Пористость: $10 \%$, поры округлые, образовавшиеся в результате выгоревшей органики, размером 0,35 мм.

Температура обжига $800-850^{\circ} \mathrm{C}$ (остатки карбоната, углистые остатки), обжиг восстановительный, кратковременный.

Обр. К-12. Плотная, тонкостенная (7 мм) керамика темно-серого цвета (рис. 3: $K-12-1-3$ ).

Состав: глины монтмориллонитовые, жирные, кластического (обломочного) материала - 5-10\%, кварц, полевой шпат.

Отощитель: дробленый кальцит (45\%), размером 0,3-1 мм, иногда встречаются отдельные зерна сростков - халцедон с кальцитом.

Пористость: 1\%, поры округлые, образовавшиеся в результате выпадения зерен, размером 0,35 мм. Температура обжига $800-850^{\circ} \mathrm{C}$ (остатки карбоната), обжиг восстановительный, кратковременный.

Обр. К-13. Плотная, тонкостенная (7 мм) керамика серо-бежевого цвета (рис. $3: K-13-1-3$ ).

Состав: глины известковые, обогащенные гидроокислами и окислами железа, тощие, кластического (обломочного) материала - 15\%, кварц, полевой шпат (ортоклаз), амфибол. Известковые остатки (60\%) представлены различными мелкими морскими раковинами, мшанками, остатками растений, размером 0,3-1,3 мм. Соотношение $\mathrm{CaO}: \mathrm{Fe}_{2} \mathrm{O}_{3}=1,5: 1,8$.

Отощитель: не использовался.

Пористость: 5\%, поры округлые, образовавшиеся в результате выпадения раковин, размером 0,351 мм. Температура обжига $800-850^{\circ} \mathrm{C}$ (остатки карбонатных раковин), обжиг слабовосстановительный, кратковременный.

Обр. К-14. Плотная, тонкостенная (7 мм) керамика розового цвета (рис. $3: K-14-1-3$ ).

Состав: глины монтмориллонитовые, жирные, кластического (обломочного) материала - 5\%, кварц, полевой шпат.

Отощитель: песок полевошпатового состава (40\%), размер зерен 0,14-0,5 мм.

Измельченный ракушечник $(25 \%)-1-1,5$ мм. Пористость: $5 \%$, поры округлые, образовавшиеся в результате выпадения раковин, размером до 1 мм. Температура обжига $800-850^{\circ} \mathrm{C}$ (остатки карбонатных раковин), обжиг окислительный, кратковременный.

Обр. К-15. Пористая, толстостенная (14 мм) темно-серого цвета, лощеная (рис. 3: $K-15-1-3$ ).

Состав: глины хлорит-смектитовые, тощие, кластического (обломочного) материала - 25\%, кварц, полевой шпат (ортоклаз).

Отощитель: песок кварц-полевошпатового состава, содержащий зерна ожелезненного песчаника (35\%), размер зерен - 0,35-1,26 мм. Шамот (25\%) представлен обломками сосудов такого же состава 0,35-1 мм.

Добавлены отдельные зерна злаковых растений, размером 1-1,25 мм, обугленные, черного цвета. Пористость: 60\%, поры округлые (газовые включения), 
образовавшиеся в результате вспенивания, размером 0,35-1 мм; поры прямоугольные и вытянутые, размером от 0,1 до 1 мм, образовавшиеся в результате выпадения зерен песка, поры овальные и вытянутее 0,05-1,25 мм, образовавшиеся в результате выгорания органических остатков.

Температура обжига $800-1000^{\circ} \mathrm{C}$ (вспенивание, остатки обуглившихся зерен), обжиг восстановительный до нейтрального (плохо выдержанный), кратковременный (1-2 ч.).

Обр. К-16. Плотная, тонкостенная (7 мм) керамика розового цвета (рис. $4: K-16-1-3$ ).

Состав: глины известково-монтмориллонитовые, обогащенные гидроокислами и окислами железа,

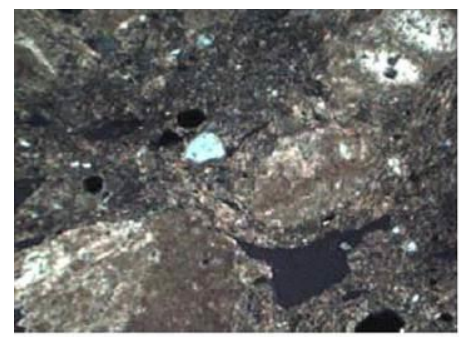

K-11

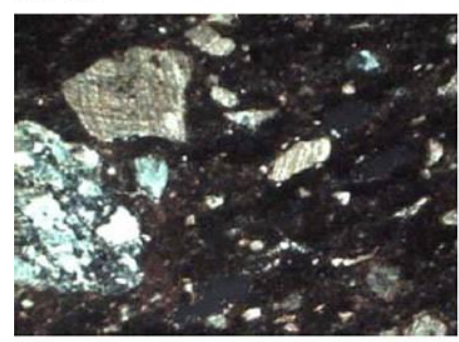

K-12

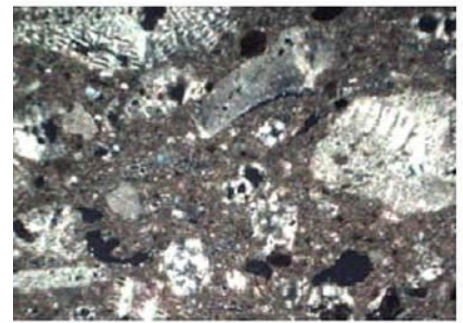

K-13

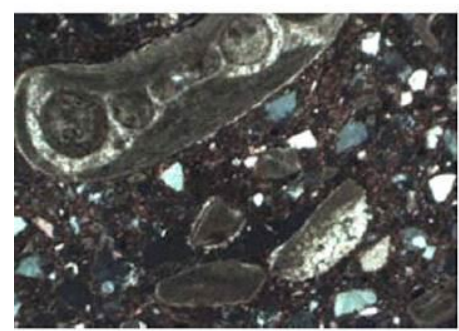

K-14 1

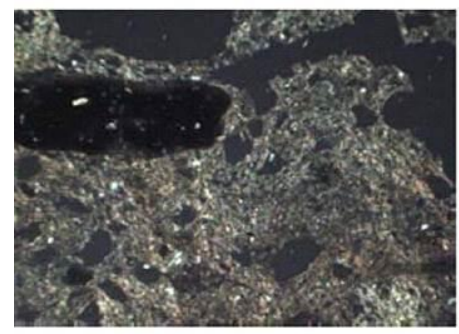

K-15 1

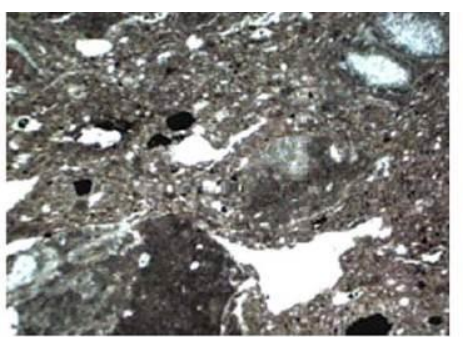

2

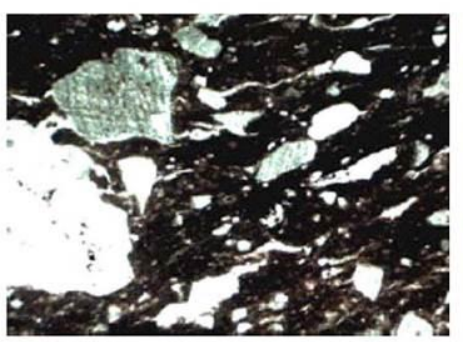

2

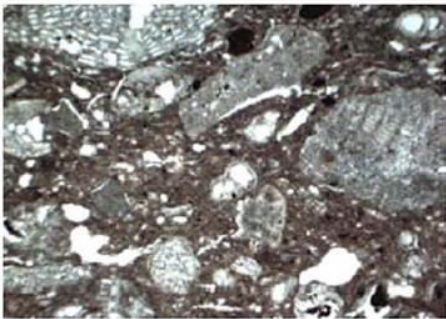

2

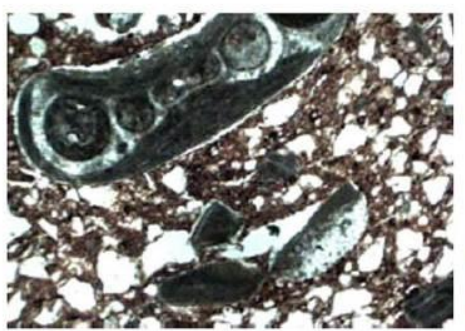

2

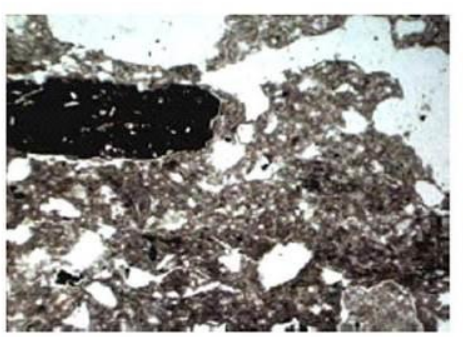

2

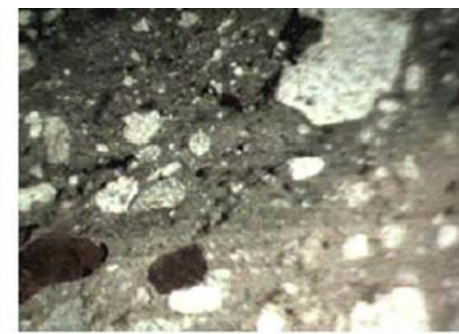

3

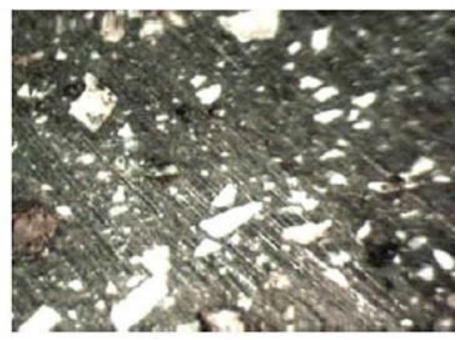

3

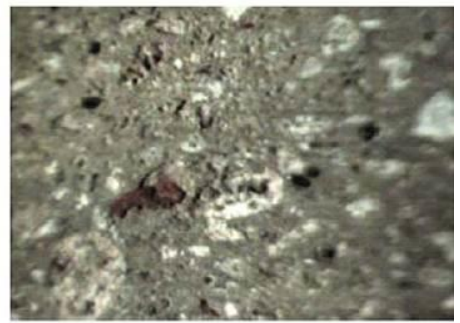

3

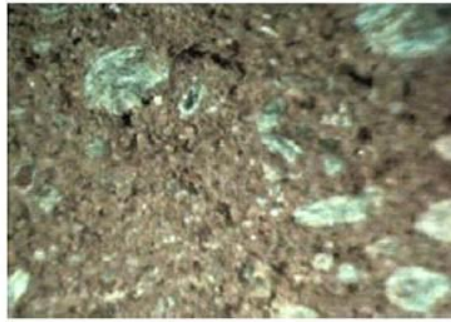

3

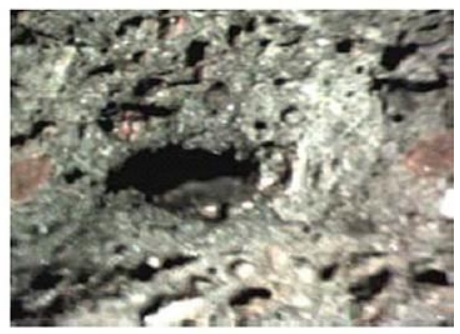

3

Рисунок 3 - Керамика из погребений курганного могильника «Клады».

Образцы керамики: $K-11 ; \kappa-12 ; \kappa-13 ; \kappa-14 ; \kappa-15$. Условные обозначения:

$1-\times 65$ (без анализаторов); 2-(в поляризационном свете); 3-×15 (под бинокуляром) 
Обр. К-18. Плотная, тонкостенная (7 мм) керамика черного цвета с тонкой обмазкой (поливой) с внешней и внутренней сторон коричневого цвета (рис. 4: $K-18-1-3$ ).

Состав: глины каолинит-гидрослюдистого состава, тощие, кластического (обломочного) материала $10 \%$, кварц, полевой шпат, слюда.

Отощитель: песок полимиктового состава (полевой шпат, кварц, слюда, карбонаты) (40\%), размер зерен 0,14-0,5 мм, некоторые зерна угловатые, плохо окатанные, отдельные зерна хорошо окатаны. Дресва карбонатных и полевошпатовых пород $(15 \%)-1$ 2 мм, шамот (10\%) - обломки керамики того же состава (2-3 мм). Пористость: 5\%, поры округлые, образовавшиеся в результате не полного выгорания органики, размером до 1 мм.

Температура обжига $800-850^{\circ} \mathrm{C}$ (остатки карбоната), обжиг в нейтральной среде, кратковременный, тонкодисперсная органика не выгорела.

Обр. К-40. Плотная, тонкостенная (5 мм) коричневого цвета, лощеная (рис. 4: $K-40-1-3$ ).
Состав: глины гидрослюдистого состава, жирные, кластического (обломочного) материала - 1\%, кварц.

Отощитель: песок полимиктового состава (полевой шпат, кварц, слюда) (60\%), размер зерен 0,10,25 мм, зерна угловатые.

Пористость: нет. Температура обжига $800-900^{\circ} \mathrm{C}$ (остатки органики), обжиг в окислительной среде, длительный.

Обр. К-150. Рыхлая, тонкостенная (7 мм) керамика черного цвета, внешняя поверхность покрыта обмазкой до 1 мм (рис. 4: $K-150-1-3$ ).

Состав: глины смешаннослойные, смектитовые, богатые органикой, жирные, кластического материала $5 \%$.

Отощитель: шамот (55\%), дробленая керамика из того же состава глин (1-4 мм). Пористость: 20\%, поры вытянутые, образовавшиеся в результате выгорания органики, размером до 2-4 мм. Температура обжига $600-700^{\circ} \mathrm{C}$ (остатки органики, тонкодисперсная органика), обжиг восстановительный, кратковременный.

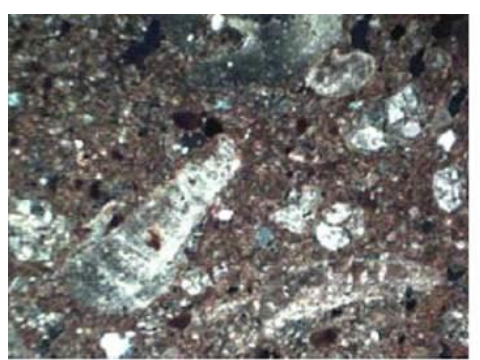

K-16 1

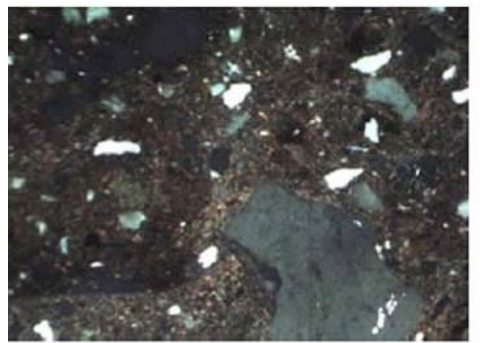

K-18 1

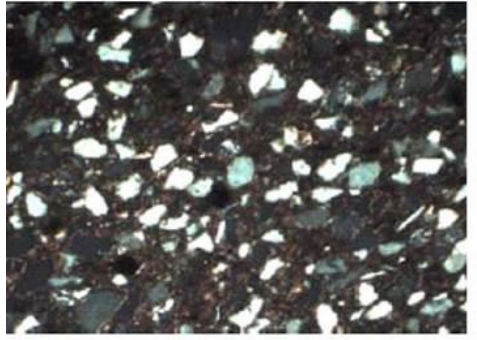

K-40 1

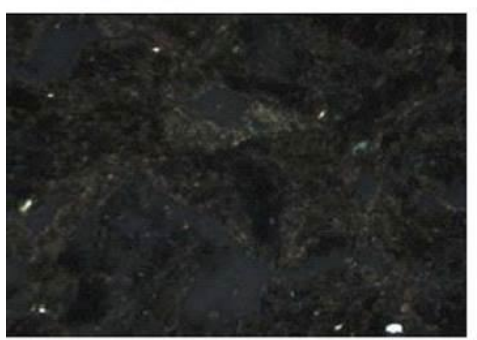

K-150 1

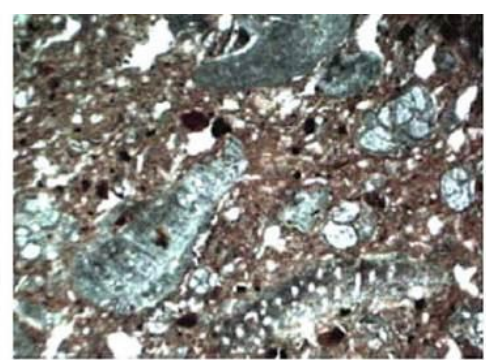

2

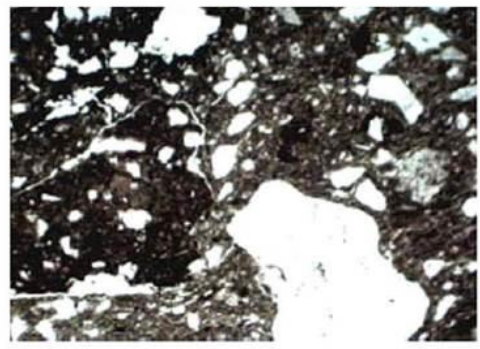

2

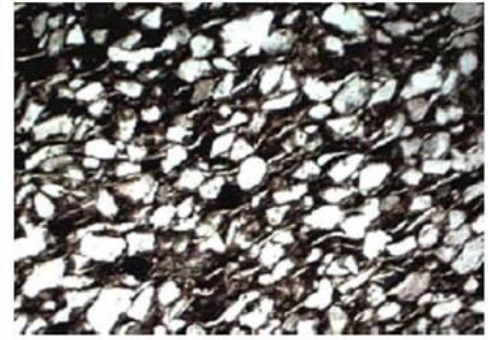

2

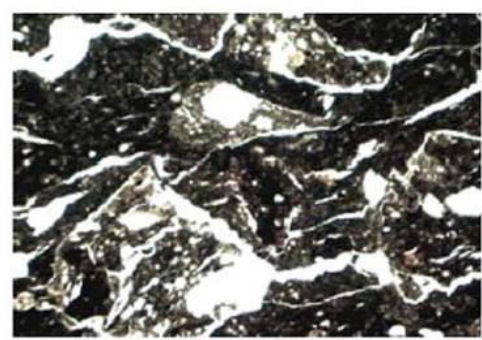

2

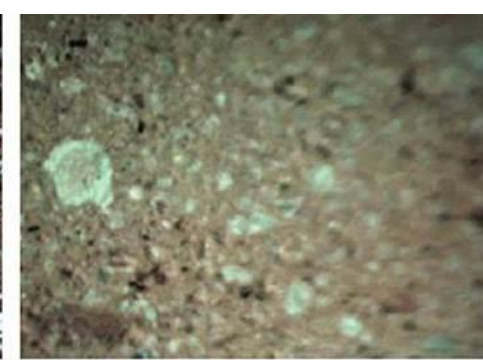

3

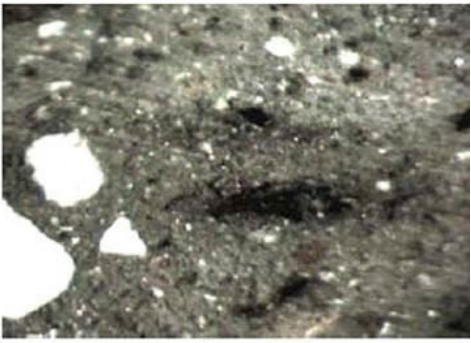

3

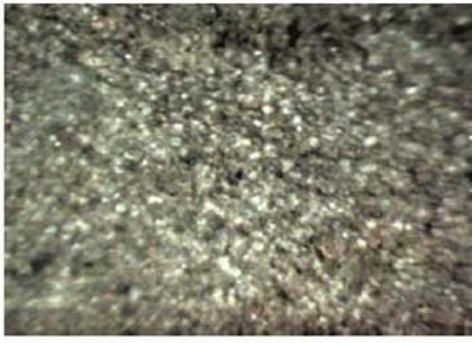

3

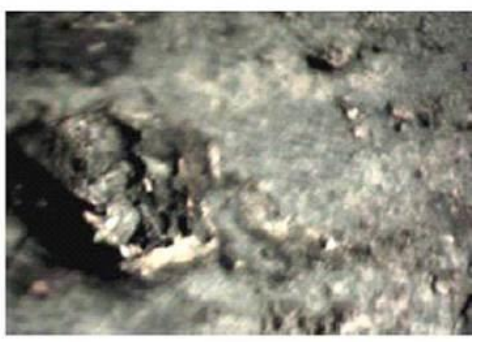

3

Рисунок 4 - Керамика из погребений курганного могильника «Клады».

Образцы керамики: $K-16 ; \kappa-18 ; \kappa-40 ; \kappa-150$. Условные обозначения:

1 - ×65 (без анализаторов); 2- (в поляризационном свете); 3-×15 (под бинокуляром) 
Петрографическому анализу были подвергнуты 19 образцов из серии погребений могильника Клады (табл. 1). Состав глин, из которой изготовлялись сосуды, гораздо более разнообразен, чем в майкопской культуре. Там применялись 5 видов глин [11, с. 134], а в новосвободненской -9 , половина - 10 - из двух видов: известковых и монтмориллонитовых и только три вида глин были того же состава, что и в майкопских сосудах (табл. 1). Набор примесей как в различных комбинациях, так и в «чистом» виде (к примеру, песок) практически одинаков - 9 и 8 (табл. 1) [11, c. 134, табл. 2]. В половине образцов - 10 случаев - в новосвободненской керамике в примесях применялся песок (табл. 1). Тогда как в сосудах майкопской культуры доля таких примесей составляет менее четвертой части - 12 из 51 [11, с. 134, табл. 2]. Практически поровну применялся окислительный и восстановительный обжиг - соответственно 10 и 9 (табл. 1). В восстановительном обжиге присутствуют только черно и серолощеные сосуды, тогда как в окислительном их только 3, остальные кирпично-красного цвета (табл. 1).

таблица 1 - Распределение примесей в керамике по способу обжига и типам глин в новосвободненской культуре

\begin{tabular}{|c|c|c|c|c|c|c|c|c|c|c|c|c|c|c|c|c|}
\hline Виды глин: & \multicolumn{2}{|c|}{$\begin{array}{l}\text { Гидро- } \\
\text { слюди- } \\
\text { стые }\end{array}$} & \multicolumn{2}{|c|}{$\begin{array}{l}\text { Известня- } \\
\text { ковые }\end{array}$} & \multicolumn{2}{|c|}{$\begin{array}{c}\text { Смектитовые } \\
\text { смешанно- } \\
\text { слойные }\end{array}$} & \multicolumn{2}{|c|}{$\begin{array}{c}\text { Каолини- } \\
\text { тов. гид- } \\
\text { рослюд. }\end{array}$} & \multicolumn{2}{|c|}{$\begin{array}{l}\text { Монтмо- } \\
\text { риллони- } \\
\text { товые }\end{array}$} & \multicolumn{2}{|c|}{$\begin{array}{c}\text { Известково- } \\
\text { монтморил- } \\
\text { лонитовые }\end{array}$} & \multicolumn{2}{|c|}{$\begin{array}{c}\text { Сме- } \\
\text { шанно- } \\
\text { слойные }\end{array}$} & \multicolumn{2}{|c|}{$\begin{array}{c}\text { Хлорит- } \\
\text { смекти- } \\
\text { товые }\end{array}$} \\
\hline Кол-во: & & 1 & & 5 & & & 3 & & & & & & & 1 & & \\
\hline $\begin{array}{l}\text { Примеси/ } \\
\text { Обжиг }\end{array}$ & оК & вос & ОК & вос & ок & вос & ок & Bос & OK & BOc & оК & вос & OK & BOC & ОК & вос \\
\hline песок+шамот & & & & & & & $1 \mathrm{c}$ & & & & & & & & & $1 \mathrm{c}$ \\
\hline шамот & & & & & & $1 \mathrm{\varphi}$ & & & & & & & & & & \\
\hline песок+дресва & & & & & & & $1 ч+$ & + & & & & & $1+c$ & + & & \\
\hline песок & 1 к & & & & & & & & $\begin{array}{c}1+\kappa \\
1 \kappa\end{array}$ & + & & & & & & \\
\hline $\begin{array}{l}\text { раковина+ } \\
\text { песок }\end{array}$ & & & & & & & & & 2 к & & & & & & & \\
\hline дресва & & & & $1 \mathrm{c}$ & & & $1 \mathrm{c}$ & & & & & & & & & \\
\hline известняк & & & & 14 & & & & & & & & & & & & \\
\hline $\begin{array}{l}\text { известняк + } \\
\text { шамот + песок }\end{array}$ & & & & 14 & & & & & & $1 \mathrm{c}$ & & & & & & \\
\hline Без примесей & & & & 1 ч $1 \mathrm{c}$ & & & & & & & $2 \kappa$ & & & & & \\
\hline Итого: & 1 & & & 5 & & 1 & 3 & & 4 & 1 & 2 & & 1 & & & 1 \\
\hline
\end{tabular}

Примечание. Цвет керамики: $ч$ - чернолощеная, $c$ - серая, $\kappa$ - красно-оранжевая. Ок - окислительный обжиг, вос - восстановительный обжиг. Знак «плюс» означает последовательный обжиг в восстановительноокислительном режиме данного экземпляра.

Данные выводы следует считать сугубо предварительными, поскольку из 6 поселений майкопской культуры выборкой взят только 51 образец [11], а из погребений новосвободненской культуры всего 19, тем более что сравнения керамики культур проводились по разным источникам: поселениям и погребениям. Но в целом очерченный диапазон в разнообразии примесей, глин, температуры и способов обжига все же дает нам достаточно определенные данные о сырье и технологии изготовления майкопской и новосвободненской керамики. М.А. Кулькова по фрагментам венчиков предполагает, что при изготовлении части майкопской керамики был использован круг. Второй автор этой точки зрения не разделяет, так как эти выводы были сделаны по фрагментам венчиков, которые прокручивались в круглодонной подставке, имитируя таким образом течение глинистой массы, внешне похожие на следы от гончарного круга. Проведенные обширные исследования Г.Н. Поплевко по майкопской керамике достаточно определенно показывают, что при изготовлении сосудов майкопской культуры круг не применялся [12-21].

\section{Список литературы:}

1. Резепкин А.Д. Новосвободненская культура. СПб., $2012.343 \mathrm{c}$.

2. Бочковой В.В., Лимберис Н.Ю., Марченко И.И., Резепкин А.Д. Поселение майкопской культуры «Чекон» // Археология и этнография понтийско-кавказского региона. Вып. 1. Краснодар: ИД НПЦ «АйтиМед», 2013. С. 5-19.
3. Кореневский С.Н. Галюгай I - поселение майкопской культуры. М.: ИД Координационно-методический центр прикладной этнографии ин-та этнологии и антропологии РАН, 1995. 189 с.

4. Кореневский С.Н. Древнейшие скотоводы и земледельцы. М.: Наука, 2004. 242 с.

5. Резепкин А.Д. Поселение эпохи ранней бронзы Чишхо и некоторые аспекты происхождения и хронологии майкопской культуры // Археолог, детектив и мыслитель. СПб., 2004. С. 422-436.

6. Резепкин А.Д. Поселение Новосвободненское // Отражение цивилизационных процессов в археологических культурах Северного Кавказа и сопредельных территорий. Юбилейные XXV Крупновские чтения: материалы междунар. науч. конф. / отв. ред. А.А. Туаллагов. Владикавказ, 2008. С. 308-311.

7. Резепкин А.Д. Поселение Новосвободненское // Археология Кавказа и Ближнего Востока. М.: ИД «Таус», 2008. С. 156-176.

8. Резепкин А.Д., Поплевко Г.Н. Классификация мисок поселений майкопской культуры // Записки ИИМК РАН № 4 / ред. Е.Н. Носов. СПб.: ИД Дмитрий Буланин, 2009. С. 81-89.

9. Резепкин А.Д. Сосуды из поселений майкопской культуры. Классификация // Новейшие открытия в археологии Северного Кавказа: исследования и интерпретации. XXVII Крупновские чтения: материалы междунар. науч. конф. Махачкала: ИД «Мавраевъ», 2012. С. 125-128. 
10. Резепкин А.Д. Жилища эпохи ранней бронзы. Поселение Новосвободненское // Записки ИИМК РАН № 7 / ред. Е.Н. Носов. СПб.: ИД Дмитрий Буланин, 2012. С. 39-45.

11. Резепкин А.Д., Кулькова М.А. Сравнительный петрографический анализ керамики из поселений майкопской культуры // XXX «Крупновские чтения» по археологии Северного Кавказа. Кавказ в системе культурных связей Евразии в древности и средневековье. Карачаевск, 2018. С. 131-134.

12. Поплевко Г.Н. Экспериментальное моделирование профилированной керамики // Новейшие открытия в археологии Северного Кавказа: исследования и интерпретации. XXVII Крупновские чтения: материалы междунар. науч. конф. Махачкала: ИД «Мавраевъ», 2012. С. 117-119.

13. Поплевко Г.Н. Технология изготовления майкопской керамики // Цивилизационные центры и первобытная периферия в эпоху раннего металла: модели взаимодействия: тезисы докладов круглого стола. М.: Институт археологии РАН, 2013. С. 29-31.

14. Поплевко Г.Н. Эксперименты по лепке профилированной керамики // Гістарычна-археалагічны зборнік. Вып. 28. Мн., 2013. С. 271-279.

15. Поплевко Г.Н. Разные технологические приемы ручного изготовления профилированной керамики // Верхнедонской археологический сборник. Вып. 6. Липецк: ЛГПУ, 2014. С. 151-157.

16. Поплевко Г.Н. Приемы ручной лепки круглодонной керамики по данным археологии, этнографии и экспериментального моделирования // Е.И. Крупнов и развитие археологии Северного Кавказа: мате- риалы XXVIII Крупновских чтений. М.: ФГБУН Институт археологии РАН, 2014. С. 88-91.

17. Поплевко Г.Н. Техника выколотки и ручная лепка сосудов без использования гончарного круга» // Труды IV (XX) всерос. археологического съезда в Казани. Т. І. Казань, 2014. С. 482-485.

18. Поплевко Г.Н. Об устойчивости культурной традиции в технологии изготовления керамики (на примере данных археологии и этнографии) // Культура русских в археологических исследованиях. Т. І. Омск - Тюмень - Екатеринбург, 2014. С. 118-124.

19. Поплевко Г.Н. Технология изготовления керамики в энеолите - раннем бронзовом веке на Северо-Западном Кавказе // Кавказ как связующее звено между Восточной Европой и Передним Востоком: диалог культур, культура диалога (к 140-летию Александра А. Миллера). СПб., 2015. С. 169-174.

20. Поплевко Г.Н. Некоторые приемы формовки майкопской керамики // Проблемы археологии Кавказа и Передней Азии. Баку, 2017. С. 176-199.

21. Поплевко Г.Н. Некоторые технологические приемы формовки и последующей обработки керамики по данным экспериментально-трасологических и этнографических исследований // XXX Крупновские чтения по археологии Северного Кавказа. Кавказ в системе культурных связей Евразии в древности и средневековье. Карачаевск, 2018. С. 125-128.

Работа выполнена при поддержке ФНИ ГАН, тема № 0184-2018-0009 «Взаимодействие древних культур Северной Евразии и цивилизаций Востока в эпоху палеометалла (IV тыс. до н.э. - I тыс. до н.э.)».

\section{MORPHOLOGICAL ANALYSIS OF NOVOSVOBODNENSKAYA CULTURE CERAMICS FROM BURIALS IN THE BURIAL MOUND «KLADY»}

(C) 2018

Rezepkin Aleksey Dmitrievich, candidate of historical sciences, senior researcher of Central Asia and Caucasus Department

Institute of History of Material Culture of the Russian Academy of Sciences (Saint Petersburg, Russian Federation)

Abstract. Morphological analysis of the ceramics of Novosobvodnenskaya culture has not been carried out so far. In this paper, 19 fragments of vessels from the burials of the burial mound «Klady» were analyzed. As a result, it was found that the composition of the clay mass used in the manufacture of ceramics was very diverse - as whole types of clays - limestone, montmorilinite, hydromica, and in their various combinations - six more variants. Almost half of the vessels (nine) were made of limestone and montmorilinite clays. The composition of impurities is also diverse: sand, chamotte, limestone and grime in various mixed versions. The last few were fragments without impurities, only four. Vessels were subjected to both oxidative roasting and reducing. Only three specimens were subjected to combined, oxidation-reduction firing. A comparative analysis of Maikop and Novosvobodnensk ceramics is carried out. Thus, this method of investigation of ceramics showed that the carriers of the Novosobvodnenskaya culture had a great experience of ceramic production, which enabled them to use a wide range of clays, in their various combinations and methods of roasting in the manufacture of ceramics.

Keywords: North Caucasus; Early Bronze Age; fourth millennium; Maikop culture; Novospobodnenskaya culture; ceramics; morphological analysis; clay species; ceramic impurity; restorative roasting; oxidizing roasting; petrographic analysis; ceramics manufacturing technology.

УДК 902.01

Статья поступила в редакцию 14.04.2018

\section{КАТАКОМБНЫЕ КУРИЛЬНИЦЫ КУРГАНОВ 1 И 4 МОГИЛЬНИКА КУНАКОВСКИЙ-2 (АНДРОПОВСКИЙ РАЙОН, СТАВРОПОЛЬСКИЙ КРАЙ)}

(C) 2018

Панасюк Наталья Викторовна, кандидат исторических наук, старший преподаватель кафедры всеобщей истории

Российский университет дружбы народов (2. Москва, Российская Федерация)

Аннотация. В статье публикуются данные о погребениях суворовской катакомбной культуры, содержащих курильницы, из могильника Кунаковский-2, исследованного экспедицией ГУП «Наследие» Ставрополь- 